\title{
Fermented Fish Entrails and Used Diaper Gel as Culture Medium of Tomato Plant (Solanum Lycopersicum)
}

\author{
CHRISTIAN STHEPHEN M. MARQUEZ ${ }^{1}$, VILMA M. GERONIMO ${ }^{2 *}$ \\ ${ }^{1}$ Pedro Guevarra Memorial National High School, \\ ${ }^{2}$ Laguna State Polytechnic University Sta Cruz Campus, Sta. Cruz Laguna \\ *Corresponding Author: VILMA M. GERONIMO, Laguna State Polytechnic University Sta Cruz \\ Campus, Sta. Cruz Laguna2
}

\begin{abstract}
The study aimed to evaluate the difference of growth of tomato plants in varying concentration of fermented fish entrails and used diaper gel as culture media. The results were interpreted using statistical tool such as mean, standard deviation, one-way analysis of variance, and Turkey Kramer's procedure. Results shows that in terms of height, tomato plants grown under the five treatments, but its height increased more on the soil with $0.11 \%$ fermented fish entrails. On the other hand, the percentage of fermented fish entrails being in the soil or diaper gel has relatively low effect on the number of leaves of tomato plants. Furthermore, in terms of wet mass, the study revealed that the $0.11 \%$ concentration of fermented fish entrails to soil produced the highest wet mass among the other treatments. It thus shows that the percentage level of fermented fish entrails and used diaper gel has significant effect on the growth of tomato plant in terms of height and wet mass, but it has no effect on its number of leaves. In the comparison of soil and diaper gel as culture media, it was found that there is a significant difference on the growth of tomato plant between the soil and diaper gel.
\end{abstract}

Keywords: Fermentation, Fertilizer, Hydrogel, Wet mass, culture media

\section{INTRODUCTION}

The battle of human to safeguard his existence enables him to develop his state of living, but the cost of his actions drastically changes his environment today. In a country like Philippines, pollution, inadequate solid waste disposal, excessive flooding in urban areas, and even loss of fertile land are results of urbanization and modernization thus most agricultural lands are converted into commercial lands.

In year 2000 the country passed the Republic Act 9003 also known as "Ecological Solid Waste Management Act of 2000", creating a mechanism to control the proper disposal of waste and emphasizes the three Rs (Reduce, Reuse and Recycle). Nationally, only $2 \%$ of waste are disposed in sanitary landfills or controlled dumps. $10 \%$ are composted, and small portions are recycled, the rest are disposed to open dumps. With this context, an urgency to create or innovate for the waste disposal using three Rs for Filipinos are encouraged.

A study conducted by Mitsubishi Securities Clean Energy Finance Committee in 2004 at Payatas dumpsite in the country, it showed that it received an average of 1,470 tons/day of Municipal Solid Waste. An analysis of the waste revealed that 3.6 percent of its composition was diaper, each child uses approximately $30 \mathrm{~kg}$ of polymer in his first two years of life, filling the landfills with around 400 $\mathrm{kg}$ of waste (Shahidian S., et. al, 2010). Using diaper gel as substitute culture medium for plants can somehow lessen the burden of waste disposal. In this study, diaper gel was used as a substitute culture medium for tomato plant.

On the other hand, the Department of Agriculture aims for the Filipino farmers to produce high value crops to enable them earn higher income. To achieve this goal, farmers are taught to go back to basic, that is to use organic fertilizer rather than the inorganic one. Fermented fish entrails as organic fertilizer is another medium used as a substitute culture for tomato plant in this study. 
The situation of waste and the condition of the environment in the Philippines aroused the interest of the researchers to turn solid wastes such as diaper and discarded fish entrails into something beneficial to field of agriculture and environment and which in turn human can be benefited.Hence, the purpose of the study is to determine the effect of fermented fish entrails and used diaper gel in the growth of tomato plant (Solanum lycopersicum). Specifically, it sought to answer the following questions:

- What percentage level of fermented fish entrails and used diaper gel is suited for the growth of tomato plant (Solanum lycopersicum)?

- What percentage level of fermented fish entrails and soil is suited for the growth of tomato plant (Solanum lycopersicum)?

- Is the percentage of the fermented fish entrails and used diaper gel have significant effect on the growth of the tomato plant (Solanum lycopersicum)?

- Is there a significant difference on the growth of tomato (Solanum lycopersicum) planted on diaper gel and on the soil?

Hydrogels have drawn great attention for use in a wide variety of biomedical applications such as cell therapeutics, wound healing, cartilage/bone regeneration and the sustained release of drugs. This is due to their biocompatibility and the similarity of their physical properties to natural tissue. (Naziha C. et al.,2015). The sustained release of many diverse species is, indeed, one of the main strength of hydrogels in the market, from gardening to genetic engineering.

As cited in the study of Yuchi M. (2012), it is presumed that, when the hydrogel is washed or dialyzed with a weak electrolytic solution such as tap water, the water absorption amount force toward the hydrogel was weakened, and the migration of water from the gel to the root hair is facilitated, thereby solve the hindrance in the root origination.

Furthermore, the effect of a hydrogel (Stoksorb K 410) on growth and ion relationships of salt resistant woody species, populus euphratica, were studied by Chen et al. (2014) wherein an addition of $0.6 \%$ hydrogel to saline soil improved seedling growth (27fold higher biomass) during a period of 2 years. Root length and surface area of treated plants was 35-fold more than those grown in untreated soil. It was reported that hydrogel treatment enhanced $\mathrm{Ca} 2+$ uptake and increased capacity of Populus euphratica to exclude salt.

The study of van Haute (2007) on the fish gills emulsion which is similar to fermented fish entrails concentrate made from a blend of saltwater fish contains about 5\% Nitrogen. On the other hand, in the study conducted by Diaz et al. (2011) on the growth and yield response of bell pepper to fish fertilizer and fermented fish fruit juice as organic fertilizer, they found that fish gills emulsion fertilizer is comparable to commercial fertilizer and may be one of the best fertilizers to be utilized for growing bell pepper. In terms of the number of leaves as growth indicator on the four treatments with 19 replications the treatment which utilizes fish fertilizers has the highest mean (528.42) compared to other treatments. In terms of height as an indicator of growth, treatment using fish fertilizer also has the best result.

Mabengwa (2013), studied the growth response of tomato to different growing media under greenhouse and field conditions. The experimental design adopted was a split plot design were different varieties assigned to the main plots and the media to subplots. The Parameter measured included vegetative varieties which includes plant height, roof canopy ratio, reproductive varieties and total fruit number per plant and total yield. The result of the study showed that; In the greenhouse, Star 9030 (Variety of tomato) grown in soil bed grew taller than other 2 varieties. The trend of these results was significant from 4 weeks after transplanting. The fruit number and weight of Star 9030 in soil was significantly higher than Rodade and Tenguru compared to other media, while the root: shoot ratio was not significantly different among the cultivars and media.

Kanallakan (2015) depicted that different growth media, plant species, and fertilizer selection will have an impact on green roof performance in Midwest United States. She evaluated different growth media such as arklite, hadite, pumice and lava with depth of 4 inches and she found out that growth media, species and fertilizer selection had an impact on percent roof coverage. 
Cox and Eaton in 2010 conducted a series of trials were used to determine which organic fertilizer (Plantex, Neptune's Fish, Daniel Pinnacle and Alfalfa pellets) is better for the growth of Marigold. Plant height and growth were compared between Plantex and Neptune Fish Fertilizers. The researcher concluded that the use of Plantex and Neptune's Fish Fertilizers resulted in the best growth of First Lady marigold.

According to (Gwon and Kim, 2012) Biodegraded Fishmeal waste Water FMW as a liquid fertilizer has been found to be a valuable resource for agriculture and feasible for commercialization. One of Local Government Unit (LGU) in Philippines, are collecting fish trashes from the market for free and process this into fish amino acids.

In addition, Maghirang, (2012) states that fish amino (FAA) acids are a good source of nitrogen for crop plants and may be used to supplement compost and manures in coastal regions which have a good supply of inexpensive fish byproducts. Some local government units (LGUs) such as Bayawan City in Negros Oriental is collecting fish trashes from the market for free and process this into FAA.

The study of Palani et. al, (2014), evaluated the effect of Gunapaselam - fermented fish waste, on the growth of Solanum melongena (Brinjal) plants. Gunapaselam prepared fermenting the fish wastes like head, gut, fins, bones etc., with Jaggery. After 15 days, the fermented liquid fish waste was filtered and used as liquid manure. Application of Gunapaselam decreased the soil $\mathrm{pH}$ and enhanced the exchangeable cation levels, organic matter and the essential plant nutrients nitrogen, phosphorus and potassium.

According to the study conducted by Forrester (2008), no difference was found on the growth of sedum plant in different depths of culture media, while Weinert Jr. (2012) said that fish fertilizer can promote seedling growth and it was supported by the finding of Diaz et al (2011) who concluded that there is no significant difference on the growth of bell pepper using fish fertilizer and inorganic fertilizer.

The studies presented supports that the growth of a plant can be influenced by different factors including the type of media, fertilizer, and the amount of nutrients.

\section{Material AND MethodS}

The experimental method of research was used in this study wherein the tests were done by exposing tomato plant (Solanum lycopersicum) to two different concentrations of culture media to determine its effect in terms of growth. While, the effect of diaper gel as culture medium on the growth of tomato plant was compared to growth of tomato plant using the soil as culture medium to determine if significant difference on the two-culture media were present.

The seeds of tomato plant were obtained from the local market. Seeds were germinated and seedlings were randomly picked and transferred into treatments with varying concentrations of culture media. Fifteen tomato plants were observed and studied of its height, number of leaves, and wet mass; there were two treatments of culture medium of fermented fish entrails and used diaper gel, and another two treatments for culture medium of fermented fish entrails and soil. Each treatment had three repetitions which contained the tomato plant samples. Figure below shows the flowchart in conducting study.

The data gathered was compiled, sorted out, organized and tabulated. The data were subjected to statistical treatment in order to answer the questions proposed by the researcher. The mean for height,wet mass and number of leaves produced on the diaper containing $0.11 \%$ and $2.87 \%$ Fermented Fish Entrails (FFE) were compared to soil containing $0.11 \%$ and $2.87 \%$ Fermented Fish Entrails to determine which treatment is suited for the growth of the tomato plant. The two formulations on the fermented fish entrail were adapted by Cabahit P. (2012) and Weinart (2012). On $2.87 \%$ formulation, it was from the study of Cabahit P. (2012) wherein he diluted 2 tablespoons or $29.574 \mathrm{ml}$ of FFE per liter of clean water to produce $2.87 \%$ concentration of fermented fish entrail. On the other hand, on the formulation of $0.11 \%$, it was prepared from Weinart (2012) wherein he diluted $3 / 4$ or $1.063 \mathrm{ml}$ of FFE per liter of clean water to produce $0.11 \%$ concentration of fermented fish entrails.

In addition, analysis of variance was used to determine if there was a significant difference on the growth of the tomato plant placed into the treatments in the diaper gel and treatments in the soil. The 
Fermented Fish Entrails and Used Diaper Gel as Culture Medium of Tomato Plant (Solanum Lycopersicum)

study also used Tukey Kramer's Procedure to further analyze which of the treatments have significantly different result.

\section{RESULTS AND DISCUSSION}

\subsection{Percentage Level of Fermented Fish Entrails and Used Diaper Gel Suited for the Growth of Tomato Plant (Solanum Lycopersicum)}

Table 1 shows the average growth of the three samples of tomato plants grown in diaper gel as culture medium in terms of height, which contained $0.11 \%$ and $2.87 \%$ of the fermented fish entrails. Over all, tomato plant grown in diaper gel that contained $0.11 \%$ has a greater average height of $14.42 \mathrm{~cm}$ as compared to $12.40 \mathrm{~cm}$ height of tomato plant grown in a diaper gel with $2.87 \%$ FFE.

Table1. Mean Height of Tomato Plant (Solanum lycopersicum) grown in $0.11 \%$ and $2.87 \%$ of Fermented Fish Entrails to Diaper Gel.

\begin{tabular}{|c|c|c|}
\hline Tomato Plant Sample & $\mathbf{0 . 1 1 \%}$ FFE Diaper Gel & $\mathbf{2 . 8 7 \%}$ FFE to Diaper Gel \\
\hline A & 14.50 & 12.00 \\
\hline B & 14.25 & 12.63 \\
\hline C & 14.50 & 12.53 \\
\hline Mean $(\mathbf{c m})$ & $\mathbf{1 4 . 4 2}$ & $\mathbf{1 2 . 4 0}$ \\
\hline
\end{tabular}

The difference in the average height indicates that $0.11 \%$ of Fermented fish entrails and diaper gel favored the growth of tomato plant. This result is in accordance to the law of the limiting factors, which explained that higher concentration of nutrients would somehow limit the growth of a plant. Klimesova et. al, (2008) cited on their study that the most frequently plants functional trait used to assess species growth response is the height.

Table 2 summarizes the number of leaves of tomato plants in the three samples grown in the diaper gel, which contained $0.11 \%$ and $2.87 \%$ of the fermented fish entrails. The table also discusses the mean number of leaves of each tomato plant sample.

Table2. Mean Number of Leaves of Solanum lycopersicum grown in $0.11 \%$ and $2.87 \%$ of Fermented Fish Entrails to Diaper Gel.

\begin{tabular}{|c|c|c|}
\hline Tomato Plants sample & $\mathbf{0 . 1 1 \%}$ FFE to Diaper Gel & $\mathbf{2 . 8 7 \%}$ FFE to Diaper Gel \\
\hline A & 6.38 & 6.13 \\
\hline B & 6.38 & 6.75 \\
\hline C & 6.75 & 5.75 \\
\hline Mean Number of Leaves & $\mathbf{6 . 5 0}$ & $\mathbf{6 . 2 1}$ \\
\hline
\end{tabular}

Noticing on the data in table 2, there is no much different in the growth of the samples, however, the result on the number of leaves as indicator of growth above is in contrary to the result of the study of Capistrano et, al. (2012) he concluded that there was a significant difference on the growth in terms of the number of leaves between the treatment of different concentrations of hugas bigas and water spinach as fertilizer. The similarity on the growth of both treatments showed that the amount of FFE has small effect on the number of leaves of tomato plants. Based from the observation conducted by the researcher it can be drawn that number of leaves as indicator of growth is not sufficient to describe the growth of tomato plants, rather the leaves width can be substituted as growth indicator.

Table 3 shows the difference in mass of tomato plant samples (A, B, C) grown in $0.11 \%$ and $2.87 \%$ of fermented fish entrails and used diaper gel.

Table3. Wet Mass of Tomato Plant (Solanum lycopersicum) grown in $0.11 \%$ and $2.87 \%$ of Fermented Fish Entrails and Diaper Gel.

\begin{tabular}{|c|c|c|c|c|c|c|}
\hline \multirow{2}{*}{$\begin{array}{c}\text { Tomato } \\
\text { plant } \\
\text { sample }\end{array}$} & \multicolumn{3}{|c|}{$\mathbf{0 . 1 1 \%}$ FFE to Diaper Gel } & \multicolumn{3}{c|}{$\mathbf{2 . 8 7 \%}$ FFE to Diaper Gel } \\
\cline { 2 - 7 } & Initial Mass & Final Mass & Difference & Initial Mass & Final Mass & Difference \\
\hline $\mathrm{A}$ & $0.36 \mathrm{~g}$ & $13.2 \mathrm{~g}$ & $\mathbf{1 2 . 9 0 g}$ & $0.35 \mathrm{~g}$ & $9.56 \mathrm{~g}$ & $\mathbf{9 . 2 1 g}$ \\
\hline $\mathrm{B}$ & $0.34 \mathrm{~g}$ & $13 \mathrm{~g}$ & $\mathbf{1 2 . 6 g}$ & $0.33 \mathrm{~g}$ & $10.00 \mathrm{~g}$ & $\mathbf{9 . 6 9 g}$ \\
\hline $\mathrm{C}$ & $9.32 \mathrm{~g}$ & $13.9 \mathrm{~g}$ & $\mathbf{1 3 . 6 g}$ & $0.34 \mathrm{~g}$ & $9.67 \mathrm{~g}$ & $\mathbf{9 . 3 3 g}$ \\
\hline
\end{tabular}

The table above shows the difference in the wet mass of tomato plants grown in $0.11 \%$ fermented fish entrails and diaper gel in samples A, B and C. As reflected in the table, the difference in wet mass of 
Fermented Fish Entrails and Used Diaper Gel as Culture Medium of Tomato Plant (Solanum Lycopersicum)

samples in $0.11 \%$ was slightly higher than the difference in wet mass of tomato plant grown in $2.87 \%$. This difference revealed that $0.11 \%$ is the percentage level suited for the growth of tomato plant. Similar study of Palani et. al (2014), revealed a significant difference in fresh plant weight in using fermented fish meal. The increase in fresh plant mass of the plant was due to the ample availability of plant nutrients, sufficient water availability that leads to the growth of the tomato plant.

\subsection{Percentage Level of Fermented Fish Entrails and Soil Suited for The Growth of Tomato Plant (Solanum lycopersicum)}

Table 4 describes the average height measured in centimeter of the three samples of tomato plants grown in the soil, which contained $0.11 \%$ and $2.87 \%$ of fermented fish entrails as well as the control setup. It shows the comparison of the growth of the samples of tomato plants in three different treatments, $0.11 \%, 2.87 \%$ and the control.

Table4. Mean Height of Solanum lycopersicum grown in $0.11 \%$ and $2.87 \%$ of Fermented Fish Entrails to Soil.

\begin{tabular}{|c|c|c|c|}
\hline Tomato Plant Sample & $\mathbf{0 . 1 1 \%}$ FFE to Soil & $\mathbf{2 . 8 7 \%}$ FFE to Soil & Soil (Control) \\
\hline A & $16.13 \mathrm{~cm}$ & 15.13 & $12.56 \mathrm{~cm}$ \\
\hline B & 17.13 & 14.56 & 12.31 \\
\hline C & 15.18 & 15.31 & 12.25 \\
\hline Mean Height & $\mathbf{1 6 . 3 5}$ & $\mathbf{1 5 . 0 0}$ & $\mathbf{1 2 . 3 8}$ \\
\hline
\end{tabular}

It is evident that the samples at $0.11 \%$ concentration of fermented fish entrails has the highest average growth in terms of height followed by $2.87 \%$ while the control set-up has the least growth. The data above shows that tomato plant grown in soil with $0.11 \%$ is most suited for the growth of tomato plant. While it is also reasonable to grow tomato plants in soil with $2.87 \%$ FFE concentration as compared to the control-setup. The result of the table above was due to the presence of major organic acids in fish fertilizer as concluded by Abassi et. al, (2009) in their study.

Table 5 summarizes the average number of leaves of tomato plants in the three samples grown in the soil, which contained $0.11 \%$ and $2.87 \%$ of the fermented fish entrails and the control set-up.

Table5. Mean Number of Leaves of Solanum lycopersicum grown in $0.11 \%$ and $2.87 \%$ of Fermented Fish Entrails to Soil.

\begin{tabular}{|c|c|c|c|}
\hline Tomato Plant Sample & $\mathbf{0 . 1 1 \%}$ FFE and Soil & $\mathbf{2 . 8 7 \%}$ FFE and Soil & Soil Control Set-Up \\
\hline A & 6.50 & 6.50 & 6.25 \\
\hline B & 6.50 & 6.63 & 5.88 \\
\hline C & 6.38 & 5.75 & 5.88 \\
\hline Mean Number of Leaves & $\mathbf{6 . 4 6}$ & $\mathbf{6 . 2 9}$ & $\mathbf{6 . 0 0}$ \\
\hline
\end{tabular}

The table above revealed that the average number of leaves of tomato plants grown in three set-ups were somewhat close. Despite the closeness of average values of number of leaves, the concentration of fermented fish entrails at $0.11 \%$ is seem to be the best culture media to grow tomato plant in comparison with the $2.87 \%$ concentration and the control set-up respectively. The number of leaves grown in $0.11 \%$ FFE to soil was similar to the study conducted by Diaz et. al, (2010) wherein the highest mean of the number of leaves fall under the treatment with low fish fertilizer concentration. These findings verified that fish fertilizer promotes the growth of tomato plant, due to the capability of organic acids contained in the FFE.

Table 6 shows the average difference in the wet mass of tomato plant grown in $0.11 \%$ and $2.87 \%$ of fermented fish entrails and the control set-up in soil. Specifically, it shows the initial and the final mass of tomato plant before and after the observation.

Table6. Wet Mass in of Tomato Plant in $0.11 \%$ and $2.87 \%$ of Fermented Fish Entrails to Soil

\begin{tabular}{|c|c|c|c|c|c|c|c|c|c|}
\hline \multirow{2}{*}{$\begin{array}{c}\text { Tomato } \\
\text { plant } \\
\text { sample }\end{array}$} & \multicolumn{2}{|c|}{$\mathbf{0 . 1 1 \%}$ FFE to Soil } & \multicolumn{2}{c|}{$\mathbf{2 . 8 7 \%}$ FFE to Soil } & \multicolumn{3}{c|}{ Control Set -Up } \\
\cline { 2 - 10 } & $\begin{array}{c}\text { Initial } \\
\text { Mass }\end{array}$ & $\begin{array}{c}\text { Final } \\
\text { Mass }\end{array}$ & Diff & $\begin{array}{c}\text { Initial } \\
\text { Mass }\end{array}$ & $\begin{array}{c}\text { Final } \\
\text { Mass }\end{array}$ & Diff & $\begin{array}{c}\text { Initial } \\
\text { Mass }\end{array}$ & $\begin{array}{c}\text { Final } \\
\text { Mass }\end{array}$ & Diff \\
\hline A & 0.33 & 14.3 & $\mathbf{1 4}$ & 0.33 & 14.2 & $\mathbf{1 3 . 9}$ & 0.31 & 10.2 & $\mathbf{9 . 9 2}$ \\
\hline B & 0.37 & 15.9 & $\mathbf{1 5 . 5}$ & 0.34 & 13.7 & $\mathbf{1 3 . 3}$ & 0.35 & 9.56 & $\mathbf{9 . 2 1}$ \\
\hline C & 0.34 & 13.9 & $\mathbf{1 3 . 6}$ & 0.36 & 14 & $\mathbf{1 3 . 6}$ & 0.33 & 9.23 & $\mathbf{8 . 9 0}$ \\
\hline \multicolumn{2}{|l}{ Mean Difference in (g) } & $\mathbf{1 4 . 3}$ & & & $\mathbf{1 3 . 6}$ & & & $\mathbf{9 . 3 4}$ \\
\hline
\end{tabular}


Fermented Fish Entrails and Used Diaper Gel as Culture Medium of Tomato Plant (Solanum Lycopersicum)

The table above shows the difference of wet of tomato plant samples grown in two concentration with the control set up. The table revealed that tomato plant grown in soil with $0.11 \%$ fermented fish entrails have the highest average mass difference of $14.3 \mathrm{~g}$ in contrast with the tomato plant grown in soil with $2.87 \%$ concentration of fermented fish entrails with an average mass of $13.6 \mathrm{~g}$ only. On the other hand, the control set-up had a mean mass of $9.34 \mathrm{~g}$ having the least among the three treatments. It was at $0.11 \%$ concentration were the tomato plant grown best in terms of mass. The result above was verified by the study conducted by Abasi, (2011), he concluded that various rates of Fish emulsions ranging from 1-4\% added to a peat-based substrate of the pot radish and cucumber seeds.

\subsection{Difference on the Growth of Tomato Plant Planted on the Diaper Gel Containing $0.11 \%$ and 2.87\% Fermented Fish Entrails}

Table 7 presents the test of significance of tomato plant (Solanum lycopersicum) grown between $0.11 \%$ and $2.87 \%$ concentration of fermented fish entrails to diaper gel. The table below revealed the $\mathrm{P}$ value of height and wet mass are less than 0.05 level of significance. This means that there is a significant difference in the growth of tomato plants between $0.11 \%$ and $2.87 \%$ concentration of fermented fish entrails and diaper gel in terms of height and wet mass.

Table7. Difference on the Growth of Tomato Plant Between 0.11\% and 2.87\% of FFE Grown in Diaper Gel

\begin{tabular}{|c|c|c|c|c|c|}
\hline $\begin{array}{c}\text { Growth } \\
\text { Indicator }\end{array}$ & $\begin{array}{c}\text { Mean of } \\
\mathbf{0 . 1 1 \%}\end{array}$ & $\begin{array}{c}\text { Mean of } \\
\mathbf{2 . 8 7 \%}\end{array}$ & F-value & P-value & Analysis \\
\hline Height & 14.42 & 12.40 & 87.934 & 0.0007 & Significantly different \\
\hline Leaves & 6.50 & 6.21 & 0.84483 & 0.4100 & Not significantly different \\
\hline Wet Mass & 13.02 & 9.41 & 136.557 & 0.0003 & Significantly Different \\
\hline
\end{tabular}

Further, analysis of the means between $0.11 \%$ FFE and 2.87\% FFE to diaper gel revealed that the right concentration was $0.11 \%$ because it facilitated the exchange of nutrients between the roots of tomato plant as compared with $2.87 \%$ concentration of FFE to diaper gel. On a similar study reported by Mori, (2012), growth of rice seeds was hindered when sown on a hydrogel containing pure water, however when hydrogel was dialyzed with tap water, which contains ions and mineral no hindrance of root origination was observed.

\subsection{Difference on the Growth of Tomato Plant Grown on Diaper Gel and on the Soil}

Table 8 shows the test of significance in the height of tomato plants grown between $0.11 \%$ and $2.87 \%$ concentration of fermented fish entrails to diaper gel and soil as culture media. The table revealed that the computed F-value of 56.42 has a $\mathrm{P}$ value of 0.000000 with 4 and 10 degrees of freedom at 0.05 level of significance.

Table8 Test of Difference on the Growth of Tomato Plants in Terms of Height Between 0.11\% and 2.87\% of FFE to Diaper gel and Soil.

\begin{tabular}{|c|c|c|c|}
\hline Treatment & Mean & F-Value & P Value \\
\hline $0.11 \%$ FFE to Diaper & Gel $14.42 \mathrm{a}$ & \multirow{2}{*}{$56.42 \%$} & 0.0000 \\
\hline $2.87 \%$ FFE to Diaper Gel & $12.40 \mathrm{~b}$ & & \\
\hline $0.11 \%$ FFE to Soil & 16.35 & & \\
\hline $2.87 \%$ FFE to Soil & $15.00 \mathrm{a}$ & & \\
\hline Control Set-up Soil & $12.38 \mathrm{~b}$ & & \\
\hline
\end{tabular}

Note: Means that share the same letter are not significantly different

This indicates a significant difference on the height of tomato plants planted on diaper and soil containing $0.11 \%$ and $2.87 \%$ concentration of fermented fish entrails. Data also reflects that $0.11 \%$ and $2.87 \%$ concentration of FFE to diaper gel as culture media were significantly different. Similarly, the $0.11 \%$ and $2.87 \%$ concentration of FFE to soil as culture media were also significantly different. This means that there is a significant difference on the growth of tomato plant in terms of height in the two-culture media containing different concentrations of FFE. Furthermore, the $0.11 \%$ FFE to diaper and $0.11 \%$ FFE to soil as culture media were significantly different; it is an indication that there is a significant difference on the growth of tomato plant between the diaper gel and soil. The same result is also true between $2.87 \%$ FFE to diaper and $2.87 \%$ FFE to soil. On the other hand, the $0.11 \%$ FFE to diaper and $2.87 \%$ FFE to soil were not significantly different, and $2.87 \%$ FFE to diaper and the 
Fermented Fish Entrails and Used Diaper Gel as Culture Medium of Tomato Plant (Solanum Lycopersicum)

control were not significantly different. This means that the plants height in this treatment grew similarly.

The difference of growth between the diaper gel as culture media and the soil as a culture media can be attributed to the bacteria which use fish emulsion as source of nutrients and precursor for plant growth regulator (Hardy et. al. 2003).

Table 9 shows the test of difference in the number of leaves of tomato plant (Solanum lycopersicum) grown between $0.11 \%$ and $2.87 \%$ concentration of fermented fish entrails to diaper gel and soil as culture media.

Table9. Test of Difference on the Growth of Tomato Plants in terms of Number of Leaves Between $0.11 \%$ and $2.87 \%$ of FFE to Diaper Gel and Soil

\begin{tabular}{|c|c|c|c|}
\hline Treatment & Mean & F-Value & P Value \\
\hline $0.11 \%$ FFE to Diaper & $6.50 \mathrm{a}$ & \multirow{2}{*}{0.43} \\
2.87\% FFE to Diaper & $6.21 \mathrm{a}$ & & \\
\hline $0.11 \%$ FFE to Soil & $6.46 \mathrm{a}$ & & \\
\hline $2.87 \%$ FFE to Soil & $6.29 \mathrm{a}$ & & \\
\hline Control Set-up Soil & $6.00 \mathrm{a}$ & & \\
\hline
\end{tabular}

Note: Means that share the same letter are not significantly different

The table shows that the computed F-value of 1.06 has a $\mathrm{P}$ value of 0.43 with 4 and 10 degrees of freedom at 0.05 level of significance. This means that there is no significant difference on the number of leaves of tomato plants grown on diaper and soil containing $0.11 \%$ and $2.87 \%$ concentration of fermented fish entrails. The result is an indication that concentration of FFE has small effect on the number of leaves in tomato plants.

Table10 shows the test of significance in the wet mass of tomato plant (Solanum lycopersicum) grown between $0.11 \%$ and $2.87 \%$ concentration of fermented fish entrails to diaper gel and soil as culture media.

Table10. Test of Difference on the Growth of Tomato Plants in terms of Wet Mass Between 0.11\% and 2.87\% of FFE to Diaper gel and Soil

\begin{tabular}{|c|c|c|c|}
\hline Treatment & Mean & \multirow{2}{*}{ F-Value } & P Value \\
\hline $0.11 \%$ FFE to Diaper & $13.02 \mathrm{a}$ & \multirow{2}{*}{50.69} & \multirow{2}{*}{0.0000} \\
\hline $2.87 \%$ FFE to Diaper Gel & $9.41 \mathrm{~b}$ & & \\
\hline $0.11 \%$ FFE to Soil & $14.36 \mathrm{a}, \mathrm{c}$ & & \\
\hline $2.87 \%$ FFE to Soil & $13.6 \mathrm{a}, \mathrm{d}$ & & \\
\hline Control Set-up Soil & $9.34 \mathrm{~b}$ & & \\
\hline
\end{tabular}

Note: Means that share the same letter are not significantly different

The table reveals that that there is a significant difference on the wet mass of tomato plants grown on diaper gel and soil containing $0.11 \%$ and $2.87 \%$ concentration of fermented fish entrails. Furthermore, the study revealed that the growth of tomato plants in $0.11 \%$ FFE and $2.87 \%$ FFE to diaper gel were significantly different. In addition, the $2.87 \%$ FFE and $0.11 \%$ FFE to soil were also significantly different; this means that growth in terms of mass in these treatments vary due to the concentration and type of culture media. The control set-up, which only contain soil, was significantly different to $0.11 \%$ and $2.87 \%$ FFE to soil.

The result above revealed that different culture media with different concentration of FFE resulted in the variation of growth of tomato plants, thus it can be said that the growth of the tomato plants is dependent on the type of media, and concentration of fertilizer used. Similarly, Kanllakan (2015), in her study concluded that plant grown in varying growth media has different growth depending on the fertilizer concentration used. This fact supported the overall result and findings of this study

\section{CONCLUSION}

The overall result of the study concluded that the percentage level of fermented fish entrails and used diaper gel has significant effect on the growth of tomato plant in terms of height and wet mass, but it 

Lycopersicum)

has no significant effect on its number of leaves. In the comparison of soil and diaper gel as culture media, it was found that there is a significant difference on the growth of tomato plant between the soil and diaper gel.

\section{REFERENCES}

[1] Abassi, P. A. Exploiting and Understanding Disease Suppressing Effects of Fish Emulsion for Soil-borne and Foliar Diseases. Ontario, Canada. Global Sciences (2014)

[2] Cox D. and Eaton T. "Organic Fertilizer use Leads to Different Growth Response, Nutrient Use, and Nitrogen Leaching by Marigold" Thesis University of the Philippines Los Banos, (2010).

[3] Kanallakan, L. "Impact of Growth Media, Species, and Fertilizer Selection on Green Roof Performance. (2015),

[4] Klimesova J., Latzel V., de Bello F. \& van Groenendael J. M. "Plant functional traits in studies of vegetation changes in response tograzing and mowing: towards a use of more specific traits". (2008)

[5] Lema, A. and Degebass, A. "Comparison of Chemical Fertilizer, fish offal's fertilizer and manure applied to tomato and onion". (2012),

[6] Maghirang . Institute of Plant Breeding - Crop Science Cluster. College of Agriculture, University of Los Banos. (2011)

[7] Mutumpike Mabengwa (2013). "Growth Response of Tomato (Lycopersicon esculentum Mil) to Different Growing Media under Greenhouse and Field Conditions".

[8] Palani et. al, (2014). Influence of Liquid Fermented Fish Waste on the Growth Characteristics of Solanum melongena.

[9] Weinert, Jr. E., Miller S.A., Ikeda D., Chang K., McGinn, J.M, \& Duponte M.W “Natural Farming: Fish Amino Acid. .,(2012)

Citation: VILMA M. GERONIMO, "Fermented Fish Entrails and Used Diaper Gel as Culture Medium of Tomato Plant (Solanum Lycopersicum)", International Journal of Research in Environmental Science (IJRES), vol. 5, no. 3, pp. 25-32, 2019. Available: DOI: http://dx.doi.org/10.20431/2454-9444.0503004

Copyright: (1) 2019 Authors. This is an open-access article distributed under the terms of the Creative Commons Attribution License, which permits unrestricted use, distribution, and reproduction in any medium, provided the original author and source are credited. 